\title{
RESISTÊNCIA AOS ANTIMICROBIANOS DE BACTÉRIAS OBTIDAS DE CARPAS (Cyprinus carpio) CULTIVADAS EM SISTEMA SEMI-INTENSIVO
}

\section{ANTIMICROBIAL DRUGS RESISTANCE OF BACTERIA FROM CARP (Cyprinus Carpio) RAISED IN A SEMI- INTENSIVE SYSTEM}

\author{
Jarbas Freitas Amarante ${ }^{1^{*}}$ \\ Lilian Kolling $^{2}$ \\ Andreia Ines Ferronato ${ }^{3}$ \\ Agueda Castangna Vargas ${ }^{3}$ \\ Mateus Matiuzzi Costa ${ }^{1}$ \\ Talita Alves Brito Amarante ${ }^{4}$ \\ 1 Universidade Federal do Vale do São Francisco, Petrolina, PE, Brasil. \\ 2Universidade Federal do Rio Grande do Sul, Porto Alegre, RS, Brasil. \\ ${ }^{3}$ Universidade Federal de Santa Maria, Santa Maria, RS, Brasil. \\ ${ }^{4}$ Universidade do Estado da Bahia, Salvador, BA, Brasil. \\ *Autor para correspondência - jarbas.amarante@univasf.edu.br
}

\section{Resumo}

Objetivando determinar o perfil de sensibilidade às drogas antimicrobianas de bactérias presentes em carpas, foi utilizado o teste de sensibilidade de difusão em disco Kirb Bauer modificado. Foram avaliados 60 isolados bacterianos, analisados e encontrados os seguintes gêneros: Staphylococcus spp. (27), Streptococcus spp. (03), Aeromonas spp. (15), Proteus spp. (04), Acinetobacter spp. (05), Pseudomonas spp. (01) e Enterobacteriaceae (05). O perfil de sensibilidade observado foi de: amicacina (35\%), amoxicilina (65\%), apramicina (32\%), ceftiofur (37\%), doxicilina (32\%), enrofloxacina (15\%), josamicina (75\%), lincomicina (37\%), nitrofurantoina (60\%), ácido nalidíxico (32\%), novobiocina (82\%), penicilina (70\%) e sulfozotrim (40\%). O índice de resistência múltipla às drogas antimicrobianas médio variou de 0,33 para Streptococcus spp até 0,71 para bactérias da família Enterobacteriaceae. Dessa forma, o maior perfil de resistência às drogas antimicrobianas testadas foi observado para novobiocina, enquanto que o menor foi observado para a enrofloxacina. Os isolados bacterianos obtidos de carpas apresentaram resistência múltipla às drogas testadas, sendo três isolados resistentes a todos os antimicrobianos testados.

Palavras-chave: aquicultura; patógenos; terapia.

\begin{abstract}
The present work has the purpose to determine the susceptibility pattern to antimicrobial drugs of bacteria isolates from carps, using Kirb Bauer modified disk diffusion test. We analyzed 60 bacterial isolates from these groups: Staphylococcus spp. (27), Streptococcus spp. (03), Aeromonas spp. (15), Proteus spp. (04), Acinetobacter spp. (05), Pseudomonas spp. (01) and Enterobacteriaceae (05). The percentual of susceptibility was: amikacine (35\%), amoxyciline (65\%), apramycin (32\%), ceftiofur
\end{abstract}


(37\%), doxycyline (32\%), enrofloxacin (15\%), josamycin (75\%), lyncomicin (37\%), nitrofurantoin $(60 \%)$, nalidixic acid (32\%), novobiocin $(82 \%)$, penicillin $(70 \%)$ and trimethoprim: sulfamethoxazole (40\%). The multiple resistance ratios to antimicrobial drugs were from 0.33 to Streptococcus spp. to 0.71 Enterobacteriaceae bacteria. Thus, the highest resistance profile of the antimicrobial drugs tested was observed for novobiocin, while the lowest was observed for enrofloxacin. Bacterial isolates from carp showed multiple resistance to the drugs tested, with three isolates resistant to all tested antimicrobials.

Keywords: aquaculture; pathogens; therapy.

Recebido em 24 de março de 2015

Aceito em 13 de novembro de 2017

\section{Introdução}

A produção mundial de peixes cultivados apresentou crescimento rápido nas últimas décadas ${ }^{(1)}$. $\mathrm{E}$ isso vem aumentando a ocorrência de contaminação microbiana, bem como a presença de substâncias tóxicas produzidas por patógenos em produtos de origem animal, despertando a atenção dos profissionais de saúde em função do aumento de agentes etiológicos de doenças alimentares. As doenças microbianas de origem alimentar são transmitidas por ingestão de alimentos e água contaminados por microrganismos patogênicos como bactérias, responsáveis pelas infecções e intoxicações alimentares ${ }^{(2)}$.

Na piscicultura, diversos microrganismos ocasionam perdas na produção do pescado, dentre eles as bactérias do gênero Aeromonas. A intensa ocorrência de Aeromonas hydrophila em lotes de truta arco-íris causa alta letalidade. Estes patógenos estão presentes na microbiota da água e de organismos aquáticos, provocando enfermidades nestes animais, causando perdas econômicas consideráveis ao produtor. Estes microrganismos são classificados como patógenos entéricos, ou extraintestinais, sendo responsáveis por quadros de meningites, endocardites, artrites, osteomielites, infecções cutâneas, agravados, sobretudo pela ação de microcrustácea parasitas, sobretudo, a lérnia ${ }^{(3)}$. Com a intensificação do cultivo de peixes, começam a surgir os problemas relacionados ao estresse que, pela redução na imunidade dos animais, possibilita um aumento na ocorrência de doenças infecciosas, tornando necessário o uso de antimicrobianos ${ }^{(4)}$.

Os antibióticos têm sido utilizados como promotores do crescimento, para profilaxia de infecções em criatórios de peixes. Todavia, têm seu emprego limitado, pois se utilizados de uma forma indiscriminada e abusiva podem acarretar no desenvolvimento de uma microbiota resistente ${ }^{(5,6)}$. A contaminação de fontes de água com resíduos de antibióticos pode ser responsável por infecções de difícil tratamento e constituir um risco a saúde pública ${ }^{(7-9)}$. Outro efeito adverso está associado à bioacumulação destes fármacos, quando administrados durante períodos longos ${ }^{(10)}$. O presente trabalho tem como objetivos determinar o perfil de sensibilidade aos antimicrobianos de isolados bacterianos de carpas (Cyprinus carpio), cultivados em sistemas semi-intensivos. 


\section{Material e Métodos}

O trabalho foi desenvolvido no Laboratório de Microbiologia Geral da Universidade do Oeste de Santa Catarina, na Cidade de Xanxerê, no Estado de Santa Catarina - SC.

Foram utilizados 60 gêneros bacterianos, sendo que 30 foram de bactérias gram positivos: entre estes 27 isolados de Staphylococcus spp. e 3 de Streptococcus spp, foram utilizados também 30 isolados de bactérias gram negativos: 15 isolados de Aeromonas spp., 4 Proteus spp., 5 de Acinetobacter spp, 1 Pseudomona spp, e 5 pertencentes à família Enterobacteriaceae.

As bactérias foram mantidas liofilizadas armazenadas na bacterioteca do laboratório até a realização dos testes.

Para verificar a viabilidade e pureza, estes foram semeados em Trypticase Soy Ágar ou Triptona Soja Ágar (TSA), sendo posteriormente incubados em estufa a $27^{\circ} \mathrm{C}$ por 48 horas.

Todos isolados considerados viáveis e puros foram submetidos ao teste de Kirby-Bauer, NCCLS (1999), em que as colônias foram retiradas de cultivo primário e em seguida repicadas em meio líquido de caldo Mueller-Hinton com incubação a $27^{\circ} \mathrm{C}$ até uma turvação referente à escala 0,5 de Mac Farland (1 x $10^{8}$ Unidades Formadoras de Colônia/ml). Com o auxílio de um swab estéril, a cultura bacteriana foi uniformemente distribuída numa placa contendo o meio de cultura sólido Mueller Hinton Ágar. Logo após, foram aplicados discos contendo antibióticos estéreis para realização do antibiograma (onde se observa a resistência ou sensibilidade de cada amostra ao antibiótico específico).

Posteriormente, as placas foram incubadas em estufa por 24 horas a $27{ }^{\circ} \mathrm{C}$. Após o período de incubação, procedeu-se à leitura da sensibilidade medindo-se o diâmetro do halo de inibição.

As drogas antimicrobianas testadas foram: amicacina $(30 \mu \mathrm{g})$, amoxilina $(10 \mu \mathrm{g})$, apramicina $(15 \mu \mathrm{g})$, ceftiofur $(30 \mu \mathrm{g})$, doxicilina $(30 \mu \mathrm{g})$, enrofloxacina $(5 \mu \mathrm{g})$, josamicina $(30 \mu \mathrm{g})$, lincomicina $(2 \mu \mathrm{g})$, nitrofurantoina $(300 \mu \mathrm{g})$, ácido nalidíxico $(30 \mu \mathrm{g})$, novobiocina $(30 \mu \mathrm{g})$, penicilina $(10 \mu \mathrm{g}) \mathrm{e}$ sulfozotrim $(25 \mu \mathrm{g})$. O índice de resistência múltipla aos antimicrobianos (IRMA) foi calculado conforme metodologia descrita por Kruperman (1983), sendo este índice determinado pela relação entre o número de antimicrobianos que a amostra é resistente e o número total de antimicrobianos testados.

Não se fez necessária submissão ao Comitê de Ética, pois os espécimes (Carpas) já se encontravam abatidos para comercialização.

\section{Resultados e Discussão}

O perfil de resistência aos agentes antimicrobianos testados, dentre os isolados avaliados, foi de: $35 \%$ para amicacina, 65\% para amoxicilina, 32\% para apramicina, 37\% para o ceftiofur, 32\% para doxicilina, $15 \%$ para enrofloxacina, $75 \%$ para josamicina, 37\% para lincomicina, $60 \%$ para nitrofurantoína, $32 \%$ para o ácido nalidíxico, $82 \%$ para novobiocina, $70 \%$ para penicilina e $40 \%$ para 
o sulfazotrim (Figura 1). Mostrando-se pelos presentes resultados que o maior nível de resistência das bactérias aos antibióticos está representado pela novobiocina e o menor representado pela enrofloxacina.

Neste estudo foram observados índices variados de resistência dos isolados obtidos de C. carpio frente aos antimicrobianos do grupo dos beta-lactâmicos (amoxicilina, doxicilina e ceftiofur). A resistência de bactérias isoladas de peixes, em particular das Aeromonas spp aos beta-lactâmicos, é bastante comum ${ }^{(5)}$. Costa et al. ${ }^{(11)}$ avaliaram a sensibilidade aos antimicrobianos de bactérias isoladas de jundiás, observando resistência de $95 \%$ dos isolados a penicilina. Várias são as estratégias de proteção bacteriana aos beta-lactâmicos, entre estes a destruição deste grupo de fármacos pela produção de beta-lactamase, diminuição da capacidade de penetração do antibiótico, assim como redução da afinidade do mesmo às PBP (Proteína ligada à penicilina) ${ }^{(12)}$.

A resistência à josamicina, droga pertencente ao grupo dos macrolídeos foi de $75 \%$. Entretanto, estudos prévios demonstraram a pouca eficiência deste grupo de fármacos antimicrobianos frente aos patógenos em aquicultura, particularmente sobre os gram negativos, que possuem resistência intrínseca $^{(5)}$. Conforme Martinez ${ }^{(13)}$, este fármaco apresenta uso no tratamento da infecção por Streptococcus spp em peixes.

Os aminoglicosídeos podem ser utilizados sozinhos ou em combinação com beta-lactâmicos para tratamento de infecções em aquicultura, embora a nefrotoxicidade destes antimicrobianos para peixes não seja bem esclarecida ${ }^{(2)}$. Em nosso estudo, os microrganismos apresentaram baixo percentual de resistência à apramicina. Os mesmos resultados foram obtidos quando a gentamicina foi à droga de estudo $\left({ }^{2,13}\right)$.

Conforme Pigarro e Santos ${ }^{(4)}$, o sulfazotrim é uma droga de bom potencial de uso na aquicultura, especialmente para o tratamento da furunculose ${ }^{(1)}$. Contudo, esta droga apresentou percentual de resistência de $40 \%$ no presente estudo, menor do que observados pelos últimos autores. Costa et al. ${ }^{(11)}$ e Silapajarn e Boyd ${ }^{(9)}$ descreveram grande resistência ao sulfazotrim em isolados obtidos de peixes.

As quinolonas são drogas de escolha em medicina veterinária para o tratamento de infecções bacterianas em peixes. Estudos têm demonstrado a resistência crescente dos microrganismos a estas $\operatorname{drogas}^{(9,11)}$. Mutações na enzima DNA girase dos microrganismos estão associadas à redução da atividade antimicrobiana ${ }^{(14)}$. O menor percentual de resistência observado foi para enrofloxacina. Segundo Smith e Hine ${ }^{(1)}$, esta droga pode ser utilizada em salmonídeos e peixes ornamentais para tratamento de infecções ocasionadas tanto por patógenos gram positivos como gram negativos. A resistência ao ácido nalidíxico encontrado no presente estudo foi à mesma descrita em estudos prévios $^{(12,2)}$. Contudo, foi maior do que a reportada por Akinboale et al. ${ }^{(5)}$.

A resistência múltipla às drogas antimicrobianas tem sido descrita em bactérias de potencial patogênico para peixes ${ }^{(6,13,15)}$. No presente estudo o índice de resistência múltipla às drogas antimicrobianas (IRMA) variou de 0,33 para Streptococcus spp. até 0,71 para bactérias da família Enterobacteriaceae (Tabela 1). Apenas um isolado de Aeromonas spp. foi sensível a todos os antimicrobianos testados, enquanto que três isolados (Enterobacteriaceae, Proteus spp. e Staphylococcus spp.) apresentaram $100 \%$ de resistência. Costa et al. ${ }^{(11)}$ observaram a resistência simultânea até seis drogas em três isolados obtidos de jundiás.

A resistência múltipla tem sido uma grande preocupação pelo fato dos antimicrobianos serem 
amplamente utilizados para prevenir ou tratar infecções microbianas nos animais e no homem e são utilizados para acelerar o crescimento e desempenho dos animais, inclusive na aquicultura ${ }^{(16)}$. O uso abusivo destas drogas está associado a diversos problemas, como o acúmulo de resíduos ilegais na carne e a proliferação de bactérias resistentes para o meio ambiente, animais e o próprio homem, representando um risco potencial à saúde pública ${ }^{(9)}$.

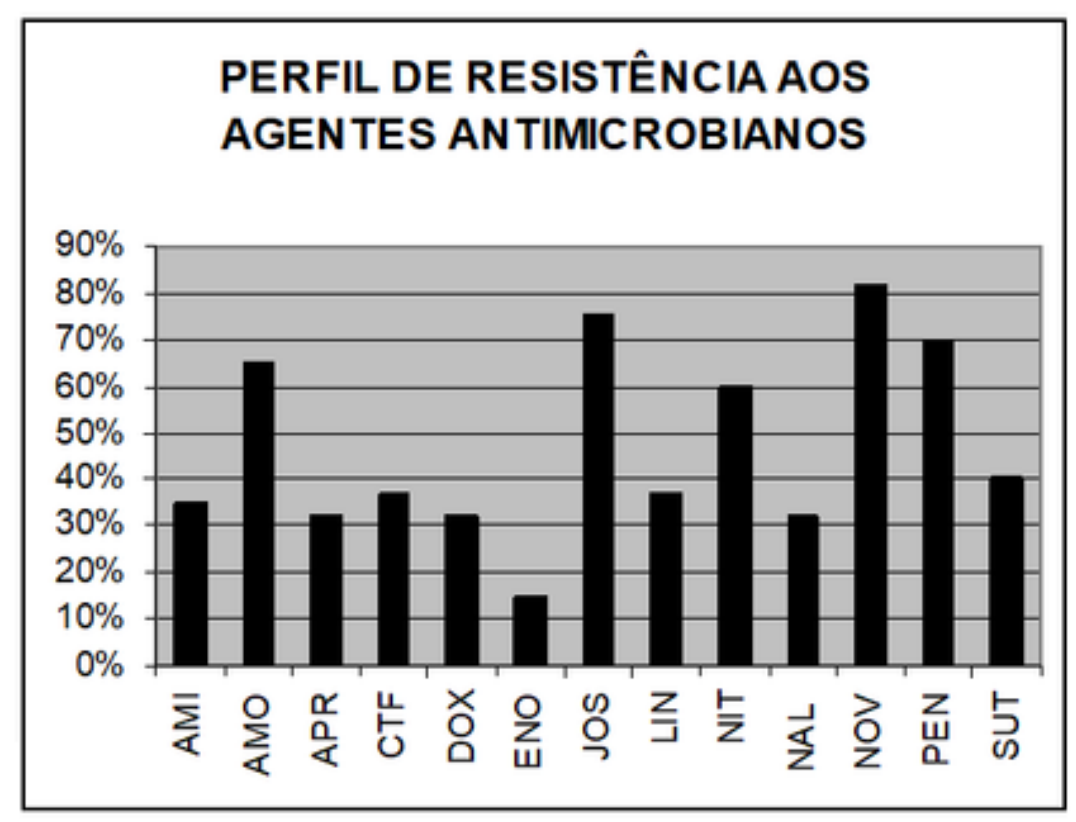

Figura 1. Perfil de resistência aos antimicrobianos de bactérias isoladas de carpas (Cyprimus carpio), onde: AMI- amicacina; AMO- amoxicilina; APR- apramicina; CTFceftiofur ; DOX -doxicilina; ENO -enrofloxacina; JOS -josamicina; LIN -lincomicina; NIT -nitrofurantoína; NAL -ácido nalidíxico; NOV -novobiocina; PEN -penicilina; SUT -sulfazotrim.

Com o crescente aumento das atividades de aquicultura, os cuidados na adoção de terapia com drogas antimicrobianas devem ser aumentados, pois pesquisas como de $\mathrm{Martinez}^{(13)}$, que mostraram um aumento significativo na resistência aos antibióticos de bactérias isoladas de rios, tanques não tratados e tanques tratados com estes fármacos. Isso reflete em alterações significativas sobre populações de outros organismos aquáticos, sobretudo, algas, alterando desta forma o equilíbrio ecológico ${ }^{(17)}$. Logo, alternativas buscando a antibioticoterapia planejada, a adoção de medidas de manejo sanitário consciente e o uso de probióticos são muito importantes para reduzir os riscos aos seres humanos e ao meio ambiente sem prejudicar, financeiramente a produção aquícola ${ }^{(6,18)}$. 
Tabela 1. Índice de resistência múltipla aos antimicrobianos (IRMA) de bactérias isoladas de carpas (Cyprinus carpio)

\begin{tabular}{lcccc}
\hline \multicolumn{1}{c}{ IRMA } & Número de isolados & Mínimo & Máximo & Médio \\
\hline Enterobacteriaceae & 05 & 0,46 & 1,00 & 0,71 \\
Aeoromonas spp. & 15 & 0,00 & 0,92 & 0,40 \\
Staphylococcus spp. & 27 & 0,08 & 1,00 & 0,42 \\
Streptococus spp. & 03 & 0,15 & 0,54 & 0,33 \\
Proteus spp. & 04 & 0,15 & 1,00 & 0,67 \\
Acinetobacter spp. & 05 & 0,31 & 0,92 & 0,69 \\
Pseudomonas spp. & 01 & 0,69 & 0,69 & 0,69 \\
\end{tabular}

\section{Conclusões}

O maior perfil de resistência às drogas antimicrobianas testadas foi observado para novobiocina, enquanto que o menor foi observado para a enrofloxacina. Os isolados bacterianos obtidos de carpas apresentaram resistência múltipla às drogas testadas, sendo três isolados resistentes a todos os antimicrobianos testados.

\section{Referências}

1. Smith P, Hine M. Towards setting break-points for oxolinic acid susceptibility of Aeromonas salmonicida using distribution of data generated by standard test protocols. Aquaculture. 2008;250(1-2):22-26.

2. Pigarro MAP, Santos M. Avaliação microbiológica da carne moída de duas redes de supermercados da cidade de Londrina- PR [Trabalho de Conclusão de Curso]. Londrina: Pós-Graduação em Higiene e Inspeção de Produtos de Origem Animal) - Instituto Qualittas, Universidade Castelo Branco; 2008.

3. Ko WC, Chiang SR, Yan JJ, Chuang YC. Comparative pathogenicity of bacteraemic isolates of Aeromonas hydrophila and Klebsiella pneumoniae. Clinical Microbiology and Infection. 2005;11(7):553-558.

4. Pathak SP, Gopal K. Occurrence of antibiotic metal resistance in bacteria from organs of river fish. Envirommental Reseach. 2005;98(1):100-103.

5. Akinboale O, Peng H, Barton MD. Antimicrobial resistance in bacteria isolated from aquaculture sources in Australia. Journal of Applied Microbiology.2006;100(5):1103-1013.

6. Cabello FC. Heavy use of prophylactic antibiotics in aquaculture: a growing problem for human and animal health and for the enviromment. Envirommental Microbiology. 2006;8(7):1137-1044.

7. De Liguoro M, Poltronieri C, Capolongo F, Montesissa C. Use of sulfadimethoxine in intensive calf farming: Evaluation of transfer to stable manure and soil. Chemosphere. 2007;68(4):671-676.

8. Sarmah AK, Meyer MT, Boxall ABA. A global perspective on the use, sales, exposure pathways, ocurrence, fate and effects of veterinary antibiotics (VAs) in the environment. Chemosphere. 2006;65(5):725-759. 
9. Silapajarn O, Boyd CE. Effects of channel catfish farming on water quality and flow in an Alabama Stream. Reviews in Fisheries Science. 2005;13(2):109-140.

10. Larsson DGJ, Pedro C, Paxaeus N. Effluent from drug manufactures contains extremely high levels of pharmaceuticals. Journal of Hazardous Materials. 2007;148(3):751-755.

11. Costa MM, Peixoto MR, Boijink LC, Castagna L, Meurer F, Vargas CA. Sensibilidade antimicrobiana de bactérias isoladas de Jundiá (Rhandia quelen). Pesquisa Veterinária Brasileira. 2008;28(10):477-480.

12. Zhanel G, Hisanaga TL, Laing NM, DeCorby MR, Nichol KA, Weshnoweski B, et al. Antibiotic resistance in Escherichia coli out patient urinary isolates: final results from the North American Urinary Tract Infection Collaborative Alliance (NAUTICA). International Journal of Antimicrobial Agents. 2006;27(6):468-475.

13. Martinez JL. The role of natural environments in the evolution of resistance traits in pathogenic bacteria. Proceedings, Biological Sciences/The Royal Society. 2009;276(1667):2521-2530.

14. Gay K, Robicsek A, Strahillevitz J, Park CH, Jacoby G, Barrett TJ, et al. Plasmid-mediated quinolone resistence in non-Typhi serotypes of Salmonella enterica. Clinical Infectious Diseases. 2006;43(3):297-304.

15. Hernandez GC, Ullloa PJ, Vergara OJA, Espejo TR, Cabello CF. Vibrio parahaemolyticus infections and algal intoxications as emergent public health problems in Chile. Revista Médica de Chile. 2005;133(9):10811088.

16. Kingombe CIB, D’Aoust J, Huys G, Hofmann L, Rao M, Kwan J. Multiplex PCR method for detection of three Aeromonas enterotoxin genes. Applied and Environmental Microbiology. 2010;76(2):425-433.

17. Galhardo L, Oliveira R. Bem-estar animal: um conceito legítimo para peixes? Revista Etologia. 2006;8(1):51-61.

18. Valenti WC. A aqüicultura brasileira é sustentável? In: IV Seminário Internacional de Aqüicultura, Maricultura e Pesca; 2008 Maio 13-15; Florianópolis, SC, Brasil. 